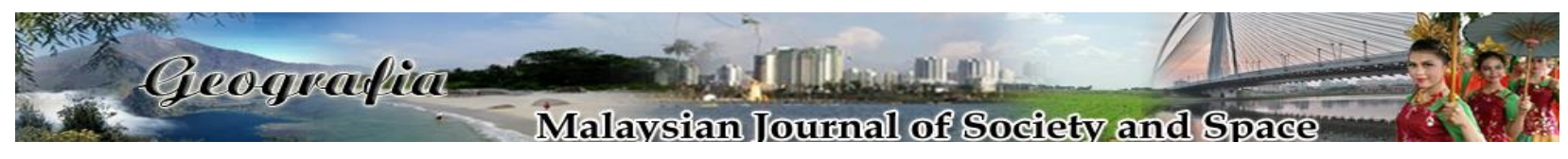

\title{
Petunjuk pembangunan komuniti orang Asli: Suatu analisis penggunaan barangan dan perkhidmatan
}

\author{
Mohd Roslan Rosnon ${ }^{1}$, Sarjit S. Gill ${ }^{1}$, Shamsul Azahari Zainal Badari ${ }^{2}$, N Alia Fahada W Ab Rahman ${ }^{3}$, \\ Adam Danial Hafiz Goh ${ }^{1}$ \\ ${ }^{1}$ Jabatan Sains Kemasyarakatan dan Pembangunan, Fakulti Ekologi Manusia, \\ Universiti Putra Malaysia \\ ${ }^{2}$ Jabatan Pengajian Pengurusan Sumber dan Pengajian Pengguna, Fakulti Ekologi Manusia, \\ Universiti Putra Malaysia \\ ${ }^{3}$ Pusat Pengajian Perniagaan dan Pengurusan Maritim, Universiti Malaysia Terengganu \\ Correspondence: Mohd Roslan Rosnon (email: roslan_rosnon@upm.edu.my)
}

Received: 18 January 2019; Accepted: 18 February 2019; Publish: 22 February 2019

\begin{abstract}
Abstrak
Arus pemodenan sedikit sebanyak mempengaruhi kehidupan masyarakat orang Asli dan mendedahkan mereka kepada dunia konsumer. Peningkatan taraf hidup dan perubahan sosial menyebabkan corak perbelanjaan barangan dan penggunaan perkhidmatan serta nilai konsumerisme sudah mula berubah mengikut peredaran masa. Oleh itu, kajian ini bertujuan menjelaskan penggunaan barangan dan perkhidmatan serta perubahan nilai dalam kalangan masyarakat orang Asli yang merupakan salah satu petunjuk kepada pembangunan komuniti. Seramai 325 orang Asli dari seluruh perkampungan orang Asli di daerah Jelebu terlibat dalam kajian ini. Reka bentuk kajian adalah secara tinjauan dengan menggunakan borang soal selidik dan pemerhatian tidak turut serta juga digunakan dalam kajian ini. Analisis kajian adalah secara deskriptif. Hasil kajian menunjukkan bahawa masyarakat orang Asli sudah mula menggunakan barangan serta perkhidmatan selari dengan arus pemodenan. Perubahan nilai tradisional kepada nilai moden sudah mula meresap dalam komuniti ini. Kesimpulannya, pembangunan yang dilakukan telah merubah kehidupan masyarakat orang Asli dengan melihat penggunaan barangan dan perkhidmatan sebagai manifestasi dalam menentukan penerimaan masyarakat orang Asli kepada arus pemodenan. Implikasinya, nilai tradisional masyarakat orang Asli sudah mula berubah ke arah nilai moden dan mereka telah menerima barangan dan perkhidmatan moden. Justeru itu, pengetahuan dan pendidikan mengenai kepenggunaan wajar diberikan kepada komuniti orang Asli agar mereka tidak menjadi mangsa hedonisme kemewahan dunia moden yang dibawa oleh arus pemodenan.
\end{abstract}

Kata kunci: arus pemodenan, barangan dan perkhidmatan, nilai konsumerisme, orang Asli, pembangunan komuniti 


\title{
Indicator of community development among orang Asli: An analysis of the usage of goods and services
}

\begin{abstract}
Modernization has, to some extent, affected the lives of indigenous peoples and exposed them to the current consumer world. The improved living standards and social changes have caused the consumption expenditure pattern on goods and services and the values of consumerism to change over time. Hence, this research aims to explain the use of goods and services, as well as the changes in values among orang Asli as a sign of community development. A total of 325 orang Asli from entire orang Asli settlement in Jelebu are involved in this research. The methods used are by doing reviews using questionnaire and also non-participant observations. The result is analysed descriptively. The result of the study shows that the orang Asli community has started using the modern goods and services. The changes in traditional to modern values has started to make its way into this community. In a nutshell the development has changed the life of orang Asli by looking at the use of modern goods and services as a manifestation in determining the acceptance of orang Asli community to modernization. The implications that can be seen are the changes of traditional toward modern values among orang Asli community and they have accepted modern goods and services. Hence, knowledge and education on the consumerism should be provided to the orang Asli community so that they will not be the victims of hedonism of the modern world of luxury brought about by modernization.
\end{abstract}

Keywords: modernization, goods and services, orang Asli, values of consumerisme, community development

\section{Pengenalan}

Komuniti orang Asli telah melalui proses arus perdana dan wujud perubahan dari segi budaya penggunaan mereka (Rosnon et al., 2018b). Pengaruh globalisasi yang turut membawa penggunaan moden sukar dihalang daripada meresap dalam komuniti seperti ini (Ma'rof \& Mohd Taufiq, 2008). Komuniti orang Asli seperti komuniti lain juga telah didedah dan terdedah kepada ekonomi tunai dan penggunaan moden dari segi penggunaan barangan dan perkhidmatan. Pengaruh tersebut telah dan sedang menyelinap masuk, walaupun lokasi petempatan komuniti ini jauh di kawasan pedalaman (Rosnon et al., 2018a; Sarjit et al., 2010).

"Dunia ialah pusat membeli-belah" telah menjadi pegangan baharu oleh pengguna dan organisasi seluruh dunia. Pengguna global hari ini membeli produk daripada jenama yang sama, daripada pengeluar yang sama dan untuk tujuan yang sama di seluruh dunia (Hawkins et al., 2007). Tidak kira di Afrika Selatan, Taiwan, Rusia atau Australia, para pengkaji menggunakan kaedah dan teori yang sama dalam menjalankan kajian dan analisa terhadap tingkah laku pengguna (Blackwell et al., 2006). Walaupun terdapat perbezaan di antara budaya dan keputusan pengguna, persamaan itu semakin kelihatan seiring dengan proses globalisasi pengguna (Blackwell et al., 2006; Hawkins et al., 2007). Masyarakat orang Asli di seluruh dunia tidak terkecuali terlibat dalam fenomena ini. Di Australia, Aboriginal and Torres Strait islander people mengalami perubahan drastik budaya kepenggunaan dan gaya hidup mereka 
(Government of South Australia, 2015; Groves, 1999). Begitu juga di Brazil, fenomena pengambilan barangan moden yang semakin jelas dan meningkat bagi golongan Xikrin-Kayapó (Mebengokre) (Gordon, 2010). Bagi golongan Maori di New Zealand, perubahan dari segi tingkah laku pengguna semakin jelas berubah selari dengan pemodenan (Love et al., 2018).

Bagi masyarakat orang Asli di Malaysia, mereka juga tidak terkecuali daripada terlibat dalam arus penggunaan perkhidmatan dan pembelian barangan yang mengikut peredaran masa. Pembangunan telah memberikan impak kepada corak perbelanjaan dan penggunaan dalam pembelian dan perkhidmatan (Gomes, 2004; Hawkins et al., 2007; Horrobin, 2006; Rosnon et al., 2018a). Penggunaan barangan dan perkhidmatan moden dalam masyarakat orang Asli memberi pemahaman tentang kedinamikan budaya yang mendasari tingkah laku penggunaan (Love et al., 2018; Ma'rof \& Mohd Taufiq, 2008; Sarjit et al., 2010). Selain itu, budaya penggunaan merupakan konsep yang digunakan untuk menerangkan keadaan apabila kegembiraan seseorang adalah dikaitkan dengan pembelian pemilikan dan penggunaan barangan (Harmsworth \& Awatere, 2013; Sarjit et al., 2010).

Walau bagaimanapun, arus pemodenan sedikit sebanyak mempengaruhi kehidupan masyarakat orang Asli dan mendedahkan mereka kepada dunia penggunaan barangan dan perkhidmatan moden. Peningkatan taraf hidup menyebabkan corak perbelanjaan barangan dan penggunaan perkhidmatan sudah mula berubah mengikut peredaran masa (Seow \& Mohd Nur Syufaat, 2018). Namun, sejauh manakah perubahan ini sudah mula menyelinap masuk dalam kalangan masyarakat orang Asli, dan adakah golongan minoriti ini dapat menerima perubahan pemodenan ini? Masyarakat orang Asli secara umumnya berbeza berbanding dengan masyarakat moden dari segi tahap pendidikan, penempatan dan tahap pendapatan mereka (Lee et al., 2018; Rosnon et al., 2018a; Seow \& Mohd Nur Syufaat, 2018). Pengetahuan mereka tentang sesuatu produk dan perkhidmatan juga terhad (Rosnon et al., 2018a, 2018b). Oleh itu, secara tidak langsung mempengaruhi cara mereka menilai sesuatu barangan atau perkhidmatan. Kadangkala, antara penyebab pengguna tidak mahu membeli sesuatu produk dapat diselidik dari segi tahap pengetahuannya atau dalam erti kata lain, kurangnya pengetahuan tentang barangan itu (Blackwell et al., 2006; Love et al., 2018; Wong, 2016).

Penggunaan barangan dan perkhidmatan moden dalam kalangan masyarakat orang Asli memerlukan satu pertimbangan yang berbeza dengan masyarakat arus perdana (Rosnon, 2010). Contohnya, kedudukan komuniti orang Asli bukan hanya terpinggir, tetapi juga majoriti daripada mereka tergolong dalam kategori miskin, bukan hanya dari segi ekonomi, tetapi juga dari segi kuasa dan pendidikan (Hassan, 2018; Rosnon, 2014; Rosnon \& Asnarulkhadi, 2018; Sarjit et al., 2010; Seow \& Mohd Nur Syufaat, 2018). Keghairahan untuk berada dalam dunia kepenggunaan menyebabkan komuniti miskin dan lemah ini menjadi mangsa budaya penggunaan itu sendiri (Rosnon et al., 2018a). Mereka sering membeli barangan dengan harga yang tinggi disebabkan oleh faktor kawasan yang jauh di pedalaman (Rosnon et al., 2018b). Mereka juga dikaitkan dengan kurangnya pengetahuan dan pengalaman dalam menguruskan wang pendapatan, khususnya dari segi merancang perbelanjaan (Ma'rof \& Mohd Taufiq, 2008; Rosnon et al., 2018b). Namun begitu, keterdedahan mereka kepada media massa dan agen sosialisasi budaya penggunaan menyebabkan mereka membentuk keperluan terhadap barangan dan perkhidmatan tersebut.

Justeru itu, perubahan nilai dan penggunaan barangan serta perkhidmatan arus perdana ini secara tidak langsung menjelaskan perubahan terhadap corak kehidupan masyarakat orang Asli. Penerimaan terhadap barangan dan perkhidmatan moden boleh dijadikan salah satu elemen bagi menjelaskan pembangunan dalam komuniti orang Asli. Walaupun terdapat pelbagai elemen lain 
seperti Rancangan Penempatan Semula (Lee et al., 2018; Mustaffa, 2008), pendidikan (Fatan, 2008; Rosnon, 2016), kesihatan (Hanina \& Asnarulkhadi, 2008) namun, penggunaan barangan serta perkhidmatan merupakan salah satu elemen sebagai petunjuk dalam pembangunan komuniti orang Asli.

\section{Kajian literatur}

Orang Asli merupakan masyarakat minoriti, baik dari segi lokasi, sosial, psikologi dan ekonomi, walaupun terdapat sesetengah komuniti ini telah diterapkan ke dalam arus perdana masyarakat Malaysia. Mereka terdiri daripada tiga kaum, iaitu Senoi, Melayu-Proto dan Negrito (Jabatan Kemajuan Orang Asli, 2016). Senoi merupakan kaum yang terbesar, iaitu dengan jumlah 97,856 orang (54.9 peratus), diikuti oleh Melayu-Proto dengan jumlah 75,332 orang (42.3 peratus) dan Negrito dengan jumlah 5,009 orang (2.8 peratus) (Jabatan Kemajuan Orang Asli, 2016).

Konsumerisme merupakan konsep yang digunakan untuk menerangkan keadaan apabila kegembiraan seseorang dikaitkan dengan pembelian pemilikan dan penggunaan barangan (Love et al., 2018; Ma'rof \& Mohd Taufiq, 2008; Wong, 2016). Konsumerisme digunakan untuk menerangkan kecenderungan manusia untuk mengidentifikasikan dirinya dengan produk dan perkhidmatan yang digunakan, terutama dengan barangan berjenama komersial yang boleh meningkatkan status seseorang, seperti barangan mewah (Batterby, 2009; Blackwell et al., 2006; Groves, 1999). Pendek kata, budaya yang diresapi oleh konsumerisme boleh dirujuk sebagai budaya pengguna (Liu-Thompkins, 2019; Ma'rof \& Mohd Taufiq, 2008; Rosnon et al., 2018a).

Konsumerisme dalam kalangan masyarakat orang Asli tidak pernah dilihat sebagai indikator pengukuran pembangunan komuniti orang Asli (Rosnon, 2010). Namun, perubahan dari segi tingkah laku perbelanjaan dan pemilikan sesuatu barangan adalah petunjuk perkembangan perubahan bagi sesebuah komuniti (Rosnon et al., 2018a). Justeru elemen ini merupakan indikator yang boleh dijadikan ukuran dalam menentukan pembangunan komuniti orang Asli. Hal ini adalah kerana melalui kepenggunaan barangan serta perkhidmatan ianya melibatkan keterbukaan kepada masyarakat orang Asli mengarus perdanakan kehidupan mereka. Kita sering menyatakan penyediaan pembangunan sosial dan infrastruktur perlu dilaksanakan dalam membangunkan masyarakat orang Asli. Namun adakah masyarakat orang Asli menggunakan perkhidmatan tersebut? Sekadar menyediakan kemudahan, adakah ianya mampu menggambarkan wujudnya pembangunan di kawasan komuniti orang Asli atau penilaian terhadap penggunaan perkhidmatan tersebut baru dikira sebagai pembangunan itu dinikmati dan dirasai. Justeru itu, makalah ini penting bagi menerangkan bahawa kepenggunaan barangan dan perkhidmatan merupakan eleman yang penting yang boleh diambil kira dalam menentukan pembangunan komuniti.

Pada hari ini, komuniti orang Asli tidak lagi boleh dianggap sebagai komuniti yang terasing, lebih-lebih lagi telah terdapat usaha kerajaan untuk mengintegrasikan mereka dalam sistem kebangsaan dan dalam pembangunan arus perdana negara (Ma'rof \& Mohd Taufiq, 2008). Usaha untuk membangunkan komuniti orang Asli dari segi ekonomi, pendidikan, kesihatan, infrastruktur fizikal sedang dilakukan kerajaan melalui agensi pembangunannya. Kehidupan dan aktiviti ekonomi mereka teradun dalam ekonomi dan pasaran kebangsaan. Dalam kata lain, pembangunan negara mempengaruhi dan mengubah gaya hidup mereka. Komuniti orang Asli sudah terlibat sebagai pengguna barang dan perkhidmatan, yang sistem pertukarannya menggunakan wang dan tidak lagi melalui sistem barter (Sarjit et al., 2010). Pemilikan dan 
penggunaan barang atau perkhidmatan mewah merupakan sebahagian daripada kehidupan mereka (Seow \& Mohd Nur Syufaat, 2018).

Oleh itu, senario ini perlu dilihat dan dianalisa dalam menilai pembangunan komuniti dalam kalangan masyarakat orang Asli. Kesimpulannya, pembangunan komuniti perlu dilihat dari segi meningkatkan kualiti dan taraf hidup kepada tahap yang lebih baik dan selesa serta membawa perubahan sosial dalam kalangan ahli komuniti dalam mendayaupayakan komuniti untuk terus maju. Elemen kepenggunaan barangan dan perkhidmatan boleh dijadikan kayu ukuran dalam menentukan pembangunan komuniti dalam kalangan masyarakat orang Asli. Hal ini adalah kerana penyediaan sahaja tidak cukup untuk dijadikan ukuran dan alasan dalam menentukan pembangunan orang Asli. Malah, kepenggunaan perlu seiring dengan penyediaan supaya pembangunan yang dirancang merupakan pembangunan yang tidak sia-sia.

\section{Metod dan kawasan kajian}

Kaedah kajian yang digunakan dalam kajian ini ialah kaedah kualitatif. Reka bentuk penyelidikan yang digunakan dalam kajian ini adalah tinjauan atau survei dengan menggunakan borang soal selidik. Kaedah ini digunakan kerana mampu untuk memberikan gambaran yang jelas untuk memahami fenomena tingkah laku manusia (Creswell, 2009). Menurut Babbie (2001), tinjauan boleh digunakan untuk objektif deskriptif. Survei adalah antara kaedah yang terbaik kepada pengkaji sains sosial yang berminat mengumpulkan data primer bagi menerangkan atau memerihalkan secara terus berkaitan populasi yang dikaji.

Dalam pengumpulan data primer, pemerhatian tidak turut serta digunakan bagi memberi nilai tambah kepada kekuatan dalam penemuan kajian. Hal ini adalah penting untuk menganalisa sesuatu keadaan yang berlaku dengan menentukan sebab musababnya (Silberg, 2001). Dalam kajian ini, pemerhatian tidak turut serta dilakukan adalah bagi melihat pemilikan barangan oleh masyarakat orang Asli. Hal ini adalah kerana kaedah pemerhatian mampu memberikan nilai tambah kepada dapatan kajian yang dijalankan melalui tinjauan yang dijalankan. Pemerhatian tidak turut serta dilakukan serentak apabila tinjauan dijalankan. Kajian dilaksanakan di seluruh perkampungan komuniti orang Asli di daerah Jelebu, Negeri Sembilan. Seramai 325 orang responden yang terlibat di seluruh perkampungan orang Asli di daerah Jelebu, Negeri Sembilan. Pemilihan responden adalah secara pensampelan mudah (convenience) iaitu ketua keluarga atau bapa, ibu dan belia. Umur responden adalah antara 18 hingga 70 tahun. Data dianalisis secara deskriptif.

\section{Hasil kajian dan perbincangan}

\section{Latar belakang demografi}

Kajian dijalankan di seluruh perkampungan orang Asli yang terletak di daerah Jelebu, Negeri Sembilan. Terdapat dua kategori perkampungan orang Asli iaitu pinggir bandar dan pedalaman. Kampung orang Asli Parit Gong, Putera, Batu 17, Ulu Kelaker, Rengoi, Sawah dan Kampung Dusun Kubur boleh dikategorikan sebagai kawasan pinggir bandar. Hal ini berdasarkan kawasan tersebut kurang daripada 10 kilometer dari jalan utama dan mempunyai ciri-ciri seperti berjiran dengan kampung orang Melayu, telah mengalami perubahan sosial yang agak jelas dan 
kebergantungan kepada hutan untuk sumber ekonomi hanya lebih kurang 10 peratus (Ramlee, 2001). Manakala, Kampung orang Asli Jeram Lesung, Bertam, Banil Tangkhoh, Kemin dan Kampung Tohor merupakan kategori kawasan pedalaman iaitu melebihi 10 kilometer dari jalan utama. Kawasan pedalaman dicirikan melebihi 10 kilometer dari jalan utama dan klasifikasi kampung ini adalah mundur (Jabatan Kemajuan Orang Asli, 2011).

Kaum utama yang menghuni kawasan kajian ialah suku kaum Temuan, yang merupakan kumpulan kaum Melayu Asli. Purata pendapatan responden adalah RM300-RM450 sebulan. Maklumat daripada JAKOA, daerah Jelebu pada bancian 2010, menunjukkan jumlah keseluruhan penduduk Kampung Orang di daerah Jelebu adalah 1280 orang. Bagi kawasan pinggir bandar, walaupun kedudukannya berhampiran dengan hutan komuniti orang Asli di kawasan pinggir merupakan komuniti yang secara relatifnya terdedah dengan kemudahan seperti bekalan air paip, bekalan elektrik, sekolah rendah, surau dan jalan raya yang menghubungkan kawasan ini dengan kawasan-kawasan lain. Data menunjukkan $41.5 \%$ daripada mereka tidak pernah bersekolah, $37.5 \%$ bersekolah rendah, dan $21.0 \%$ bersekolah menengah. Bagi yang tidak bersekolah, hal ini kerana kanak-kanak di kawasan ini lebih cenderung menolong ibu bapa mereka di kebun getah dan mengutip hasil hutan, seperti pucuk paku dan daun pisang. Berdasarkan anutan kepercayaan, umumnya majoriti penduduk beragama animisme, namun terdapat dalam kalangan mereka yang beragama Islam dan Kristian.

\section{Penggunaan barangan dan perkhidmatan sebagai petunjuk pembangunan komuniti}

Dalam makalah ini, pembangunan sesebuah komuniti dapat dilihat melalui dua aspek iaitu pembangunan komuniti secara dalaman dan fizikal. Arus pemodenan membawa masyarakat orang Asli kepada satu norma perubahan dalam aplikasi kemudahan dan amalan kehidupan seharian ke arah kehidupan yang lebih moden dan selesa. Makalah ini memfokuskan penggunaan barangan dan perkhidmatan komuniti orang Asli sebagai salah satu petunjuk kepada pembangunan komuniti dari dua elemen iaitu pembangunan dalaman dan pembangunan fizikal. Setelah 60 tahun Malaysia merdeka pembangunan komuniti orang Asli tidak pernah dilupakan seiring dengan pembangunan yang lain (Rosnon \& Asnarulkhadi, 2018). Disebabkan beberapa faktor yang menjadi kekangan terhadap penyampaian pembangunan menjadikan komuniti orang Asli lambat menerima pembangunan. Namun, tidak dinafikan bahawa masyarakat orang Asli sudah mula menerima serta terdedah dengan pembangunan dan perkhidmatan moden yang disediakan dalam menjalani kehidupan yang lebih selesa dan moden.

\section{a. Perubahan nilai konsumerisme}

Mengenai perubahan nilai dalam kehidupan masyarakat orang Asli, mereka merupakan komuniti yang dianggap unik kerana pengamalan nilai tradisional yang sangat mendalam dalam kehidupan seharian (Hassan, 2000). Dalam era globalisasi yang serba kompetatif, amalan hidup masyarakat orang Asli tidak kira dalam mahupun luar bandar serta pedalaman, asimilasi nilai moden dan tradisional berlaku demi memenuhi kesesuaian dan kehendak semasa selaras dengan aliran zaman. Perubahan nilai ke arah yang yang positif perlu dikekalkan dalam usaha mewujudkan suasana kehidupan yang harmoni dan bertaraf tinggi. Bukan bermakna demi membangunkan nilai hidup, nilai-nilai tradisional perlu ditinggalkan, tetapi penambahbaikan perlu berlaku agar segala keunikan yang ada dapat dikekalkan dan diserikan lagi dengan nilai-nilai moden yang meningkatkan mutu dan kualiti hidup. 
Dalam konteks perubahan nilai penggunaan, nilai ini memberi satu pengaruh yang sangat besar dalam pembangunan nilai kehidupan komuniti orang Asli. Antara pengaruh yang paling ketara adalah terhadap pengamalan nilai tradisional orang Asli. Hal ini berlaku akibat terjahan konsep-konsep baru dalam menjalani kehidupan seharian. Sebagai contoh, ketika dahulu komuniti orang Asli mendapatkan khidmat pawang atau bomoh bagi merawat setiap jenis penyakit kerana mereka percaya simptom tersebut berlaku akibat kuasa dan pengaruh alam serta roh-roh yang tidak tenteram (Hassan, 1998). Nilai tradisional ini kian terhakis akibat kemajuan sains dan teknologi perubatan yang menawarkan khidmat rawatan secara moden dan menyediakan prosedur rawatan yang lebih selesa dan berkesan dalam jangka masa yang singkat.

Kebanyakan orang Asli kini lebih cenderung untuk mendapatkan khidmat doktor bagi merawat penyakit-penyakit yang dihidapi. Dapatan kajian menunjukkan bahawa 92.6\% masyarakat orang Asli pergi ke klinik atau hospital jika sakit. Mereka tidak mempunyai masalah untuk menggunakan ubat-ubatan moden yang asing bagi mereka. Penggunaan khidmat pawang di kawasan mereka kian terhad kepada rawatan berkaitan gangguan semangat dan sakit dalaman. Walaupun situasi ini menunjukkan penghakisan nilai tradisional, perkembangan nilai moden telah berlaku apabila nilai hidup yang mementingkan kesihatan kian berkembang dalam komuniti orang Asli. Perkembangan nilai ini merupakan salah satu pertunjuk yang baik kepada perubahan hidup masyarakat orang Asli kepada hidup yang lebih sihat dan berkualiti.

Perkembangan nilai hidup masyarakat orang Asli juga boleh dilihat apabila mereka terdedah kepada kemajuan teknologi hari ini. Perkara ini menawarkan wadah berbentuk hiburan dan informasi. Peningkatan aplikasi teknologi dalam kalangan orang Asli akan membawa kepada pengaruh budaya hedonisme dalam kehidupan mereka. Budaya hedonisme sering berlaku di kawasan bandar apabila kebanyakan belia dahaga akan hiburan dalam pelbagai bentuk. Hal ini juga berlaku kepada komuniti orang Asli yang tinggal di kawasan pinggir dan juga pedalaman. Peningkatan aplikasi teknologi sebagai contoh penggunaan Astro iaitu 21.5\% dan internet iaitu 2.5\% dalam kalangan komuniti orang Asli, menyediakan ruang dan peluang kepada elemen hedonisme untuk berkembang dalam komuniti orang Asli. Perkembangan nilai berbentuk hiburan ini bukanlah satu perkara yang negatif. Budaya seperti ini menawarkan pengetahuan mengenai budaya luar dan perkembangan hiburan semasa. Namun kawalan dan pemantauan perlu dilakukan bagi mengelakkan kebenjatan budaya berlaku dalam komuniti orang Asli. Justeru perkembangan ini telah menunjukkan satu perubahan nilai dalam kalangan masyarakat orang Asli sehingga menunjukkan pembangunan arus perdana sudah meresap masuk ke dalam komuniti orang Asli.

Nilai penggunaan dari segi makanan segera juga dilihat berkembang dalam komuniti Orang Asli. Penggunaan perkhidmatan makanan segera seperti KFC iaitu $27.1 \%$ dan McDonalds $17.2 \%$. Selain itu, masyarakat orang Asli sudah mula membeli belah di pasaraya besar seperti Tesco iaitu 18.8\%, Giant iaitu 20.9\% dan Carrefour iaitu 11.7\% (Jadual 1). Dapatan kajian ini mencerminkan sikap orang Asli yang sudah menerima segala bentuk pembaharuan dan pemodenan. Keadaaan ini juga menunjukkan komuniti orang Asli sudah memikirkan soal kualiti dan kepuasan penggunaan sesuatu perkhidmatan dalam aktiviti harian. Kemudahan dalam perkhidmatan moden menarik minat masyarakat orang Asli untuk merasai sendiri nikmat penggunaan perkhidmatan tersebut. Hal ini menunjukkan penerimaan mereka terhadap pembangunan yang dirancang dalam mencapai negara maju.

Perkembangan nilai kehidupan orang Asli telah melonjakkan taraf kehidupan mereka kepada taraf kehidupan yang lebih baik. Pemodenan membawa pelbagai bentuk kemajuan yang secara tidak langsung menerapkan nilai-nilai baharu yang membawa kebaikan dalam kehidupan 
mereka. Walaupun timbul pendapat nilai-nilai tradisional akan terhakis akibat pengaruh budaya baharu, hal ini tidak semestinya berlaku sekiranya wujud mekanisme yang dapat mengimbangi nilai kehidupan tradisional dan moden komuniti orang Asli. Pemeliharaan budaya hidup mereka perlu dipergiat agar, arus pemodenan tidak menelan amalan tradisi mereka yang unik dan istimewa.

Jadual 1. Penggunaan perkhidmatan makanan dan keperluan harian

\begin{tabular}{lcc}
\hline \multicolumn{1}{c}{ Perkhidmatan } & \multicolumn{2}{c}{ Berbelanja / Penggunaan } \\
\cline { 2 - 3 } & $\begin{array}{c}\text { Ya } \\
\mathbf{n}(\boldsymbol{\%})\end{array}$ & $\begin{array}{c}\text { Tidak } \\
\mathbf{n}(\boldsymbol{\%})\end{array}$ \\
\hline Makanan: & & \\
KFC & $88(27.1)$ & $237(72.9)$ \\
McDonald's & $56(17.2)$ & $269(82.8)$ \\
Pizza Hut & $46(14.2)$ & $279(85.8)$ \\
Keperluan harian: & & \\
Tesco & $61(18.8)$ & $264(81.2)$ \\
Giant & $68(20.9)$ & $257(79.1)$ \\
Carrefour & $38(11.7)$ & $287(88.3)$ \\
Econsave & $38(11.7)$ & $287(88.3)$ \\
Mydin & $41(12.6)$ & $284(87.4)$ \\
\hline
\end{tabular}

b. Pembangunan fizikal

Berdasarkan aspek pembangunan fizikal, makalah ini lebih memberi fokus terhadap aplikasi infrastruktur yang disediakan kepada masyarakat orang Asli dalam kehidupan seharian mereka. Terdapat beberapa infrastruktur asas yang digunakan sebagai elemen untuk melihat konsumerisme orang Asli. Kini, komuniti orang Asli tidak lagi kekok untuk menerima pembaharuan dan menggunakan setiap pembangunan yang diberikan. Penerimaan ini dapat dilihat dari segi penggunaan dan pemilikkan kelengkapan isi rumah, teknologi telekomunikasi, pengangkutan, perkhidmatan perubatan, pusat beli-belah, dan perkhidmatan simpanan. Kesemua elemen ini merupakan elemen-elemen yang wujud dalam pembangunan pemodenan sesebuah negara.

\section{(i) Kelengkapan rumah}

Dapatan kajian menunjukkan bahawa masyarakat orang Asli sudah mula menggunakan dan memiliki kelengkapan rumah seperti keperluan tempat tidur yang selesa, barangan elektronik, dan kelengkapan dapur dan sebagainya. Dapatan kajian juga menunjukkan masyarakat orang Asli telah menerima dan menggunakan kemudahan asas dalam menjalani kehidupan seharian. Proses asimilasi telah berlaku dalam kehidupan mereka apabila perkara-perkara asas yang memberi keselesaan dalam kehidupan telah diterima oleh masyarakat orang Asli. Dapur memasak elektrik menunjukkan pemilikan sebanyak $75.4 \%$, mesin basuh $24.6 \%$, peti sejuk $36.6 \%$, periuk nasi elektrik $34.8 \%$ dan barangan elektrik dapur lain (pengisar atau blender dan oven) $26.8 \%$. Hal ini menunjukkan kehidupan orang Asli yang sudah mula bergantung dengan kemudahan perkakas elektrik dan mula meninggalkan cara tradisional untuk melakukan aktiviti memasak, penyediaan makanan dan sebagainya. Jika dahulu kehidupan mereka hanya bergantung kepada kayu api dan daun-daun keras bagi dijadikan kipas, kini tidak lagi kerana pemodenan telah membawa kehidupan mereka ke arah kehidupan yang lebih mudah dan 
menjimatkan masa (Hassan, 2000; Mustaffa, 2008). Walaupun beberapa perkakas elektrik yang lain mencatatkan peratusan yang rendah seperti penghawa dingin $(0.9 \%)$ dan barangan elektrik berjenama daripada Seng Heng iaitu 6.8\%. Namun, tidak dapat dinafikan bahawa komuniti orang Asli hari ini sudah berubah ke satu tahap pemodenan dalam kehidupan mereka.

Komuniti orang Asli sudah meneroka dunia moden dengan menjadikan penggunaan alatan elektrik dan elektronik serta kemudahan asas isi rumah sebagai sebahagian dari kehidupan mereka. Mereka menggunakan perkakas elektrik yang memudahkan kehidupan seharian, menggunakan perabot tempat tidur (34.5\%) dan perabot ruang tamu (28.9\%) bagi menjalani aktiviti di rumah dengan selesa dan menggunakan barangan elektronik seperti telefon bimbit $(52.3 \%)$ dan televisyen $(71.1 \%)$ untuk memudahkan urusan perhubungan dan mendapatkan hiburan serta maklumat dalam kehidupan seharian. Aplikasi seperti ini boleh meningkatkan mutu kehidupan mereka sebagai komuniti yang tinggal di luar bandar. Senario ini menjelaskan bahawa penggunaan barangan dan perkhidmatan merupakan salah satu petunjuk kepada pembangunan komuniti dalam kalangan masyarakat orang Asli. Jadual 2 menunjukkan dapatan kajian dari segi kelengkapan rumah.

Jadual 2. Penggunaan dan pemilikan barangan kelengkapan rumah

\begin{tabular}{|c|c|c|}
\hline \multirow[t]{2}{*}{ Barangan } & \multicolumn{2}{|c|}{ Berbelanja / Pemilikan } \\
\hline & $\begin{array}{c}\text { Ya } \\
\mathbf{n}(\%)\end{array}$ & $\begin{array}{c}\text { Tidak } \\
\text { n }(\%)\end{array}$ \\
\hline \multicolumn{3}{|l|}{ Perabot: } \\
\hline Set sofa & $67(20.6)$ & $258(79.4)$ \\
\hline Kelengkapan dapur (meja makan) & $90(27.7)$ & $235(72.3)$ \\
\hline Kelengkapan bilik tidur & $112(34.5)$ & $213(65.5)$ \\
\hline Perabot ruang tamu & $94(28.9)$ & $231(71.1)$ \\
\hline Perabot Courts Mammoth & $30(9.2)$ & $295(90.8)$ \\
\hline \multicolumn{3}{|l|}{ Barangan elektrik: } \\
\hline Mesin basuh & $80(24.6)$ & $245(75.4)$ \\
\hline Peti sejuk & $119(36.6)$ & $206(63.4)$ \\
\hline Periuk nasi elektrik & $113(34.8)$ & $212(65.2)$ \\
\hline Barangan elektrik dapur (pengisar (blender), oven) & $87(26.8)$ & $238(73.2)$ \\
\hline Penyaman udara & $3(0.9)$ & $322(99.1)$ \\
\hline Kipas elektrik & $149(45.8)$ & $176(54.2)$ \\
\hline Dapur memasak & $245(75.4)$ & $80(24.6)$ \\
\hline Barangan elektrik Singer & $74(22.8)$ & $251(77.2)$ \\
\hline Barangan elektrik Seng Heng & $21(6.8)$ & $303(3.2)$ \\
\hline
\end{tabular}

\section{(ii) Telekomunikasi}

Pemodenan masa kini menyebabkan infrastruktur telekomunikasi merupakan antara yang penting dalam kehidupan. Kerajaan hari ini bertungkus lumus meningkatkan liputan kemudahan telekomunikasi tidak kira di bandar dan luar bandar. Menyedari kepentingan kemudahan telekomunikasi, masyarakat orang Asli hari ini tidak terlepas daripada keinginan merasai nikmat pemodenan yang disediakan. Capaian liputan diperluas ke kawasan luar bandar supaya kemudahan ini dapat digunakan oleh semua lapisan masyarakat. Aplikasi teknologi seperti Astro memberi kemudahan penggunaan sehingga ke kawasan pedalaman. Pencawang telekomunikasi dibina di kawasan pedalaman bagi menyediakan liputan yang menyeluruh kepada komuniti orang Asli. Keadaan ini telah menyediakan satu platform untuk komuniti orang Asli meneroka kemudahan baru yang tersedia bagi meningkatkan kualiti kehidupan mereka. 
Melihat kepada penggunaan kemudahan seperti Astro dan inet, walaupun statistik penggunaan masih berada dalam peratusan yang rendah iaitu di bawah $50.0 \%$ dari keseluruhan responden. Namun, hal ini dapat menjelaskan bahawa telekomunikasi moden sudah mula diterima oleh masyarakat orang Asli. Justeru itu, pembangunan telah mula berkembang dalam komuniti orang Asli. Dapatan kajian menunjukkan penggunaan pekhidmatan Astro sebanyak 21.5\%. Walaupun terdapat kekangan seperti masalah kewangan, komuniti orang Asli tidak menjadikan perkara tersebut sebagai alasan untuk tidak menerima arus pemodenan, malah kebanyakan mereka berkongsi penggunaan perkhidmatan tersebut bersama jiran tetangga bagi mengatasi kekangan kemampuan kewangan bagi membayar kos perkhidmatan.

Begitu juga dalam perkhidmatan jalur lebar internet, walaupun penggunaannya hanyalah sebanyak $2.5 \%$ keadaan ini sudah melambangkan penerimaan orang Asli terhadap kemudahan jalur lebar internet. Justeru penggunaan perkhidmatan ini menjadi salah satu petunjuk kepada pembangunan komuniti dari segi penggunaan ICT dalam kalangan masyarakat orang Asli. Penggunaan perkakas elektronik seperti telefon bimbit $(50.5 \%)$, televisyen $(71 \%)$, radio $(50.5 \%)$, dan pemain cakera padat (44\%) (Jadual 3). Hal ini menunjukkan komuniti orang Asli telah menggunakan perkhidmatan perhubungan seperti telefon bimbit dan mendapatkan maklumat tentang dunia luar melalui televisyen dan radio. Arus pemodenan yang berlaku tidak pernah sesekali meninggalkan komuniti orang Asli. Kehidupan mereka terkesan secara tidak langsung dalam kemajuan yang dikecapi negara. Perkara-perkara yang dulunya tidak menjadi keperluan dalam hidup mereka sudah bertukar menjadi sesuatu yang penting untuk dimiliki dan digunakan seiring dengan perkembangan semasa.

Jadual 3. Penggunaan dan pemilikan barangan elektronik dan perkhidmatan telekomunikasi

\begin{tabular}{lcc}
\hline \multicolumn{1}{c}{ Perkhidmatan dan barangan } & \multicolumn{2}{c}{ Penggunaan / Pemilikan } \\
\cline { 2 - 3 } & $\begin{array}{c}\text { Ya } \\
\mathbf{n}(\%)\end{array}$ & $\begin{array}{c}\text { Tidak } \\
\mathbf{n}(\%)\end{array}$ \\
\hline Telekomunikasi: & $70(21.5)$ & $255(78.5)$ \\
$\quad$ Astro & $8(2.5)$ & $317(97.5)$ \\
$\quad$ Internet & & \\
Barangan elektronik: & $231(71.1)$ & $94(28.9)$ \\
$\quad$ Televisyen & $164(50.5)$ & $161(49.5)$ \\
Radio & $143(44)$ & $182(56)$ \\
Video/VCD/DVD & $170(52.3)$ & $155(47.7)$ \\
Telefon bimbit & $18(5.5)$ & $307(94.5)$ \\
Komputer & $19(5.8)$ & $3064.2)$ \\
Video kamera/ kamera & & \\
\hline
\end{tabular}

\section{(iii) Pengangkutan}

Dapatan kajian menunjukkan pengangkutan yang dimiliki oleh orang Asli yang tertinggi ialah motosikal iaitu $84.3 \%$, diikuti dengan kereta sebanyak 18.2\%. Faktor kewangan menyebabkan pemilikan kereta adalah rendah dalam kalangan mereka. Faktor jalan yang sempit dan berliku juga menyebabkan pemilikan motosikal berada pada peratusan yang tinggi. Hal ini membuktikan komuniti orang Asli menggunakan kenderaan bagi memudahkan perhubungan mereka untuk bergerak. Bagi perkhidmatan pengangkutan awam, perkhidmatannya adalah lebih terfokus kepada penggunaan teksi iaitu 55.4\%. Meskipun perkhidmatan bas ekspress, keretapi dan LRT tidak disediakan di tempat mereka, hal ini sedikit pun tidak menjadi penghalang kepada 
masyarakat orang Asli merasai dan menggunakan perkhidmatan tersebut untuk memudahkan perhubungan mereka ke tempat lain di bandar. Berdasarkan penggunaan perkhidmatan pengangkutan, seramai $50.5 \%$ orang responden pernah menggunakan perkhidmatan bas ekspres, $18.8 \%$ orang responden menggunakan komuter atau kereta api dan $12.6 \%$ orang responden pernah menggunakan perkhidmatan LRT. Hasil kajian ini telah membuktikan penggunaan perkhidmatan pengangkutan moden telah merentasi komuniti orang Asli. Walaupun penempatan di kawasan pedalaman namun, pengangkutan moden seperti LRT dan sebagainya sudah menyelinap masuk dalam kalangan masyarakat orang Asli. Justeru itu, penggunaan perkhidmatan ini menjadi salah satu petunjuk kepada pembangunan komuniti masyarakat orang Asli. Jadual 4 menunjukkan pemilikan kenderaan dan penggunaan perkhidmatan pengangkutan.

Jadual 4. Pemilikan kenderaan dan penggunaan perkhidmatan pengangkutan

\begin{tabular}{lcc}
\hline \multicolumn{1}{c}{ Barangan dan perkhidmatan } & \multicolumn{2}{c}{ Pemilikan / Penggunaan } \\
\cline { 2 - 3 } & $\begin{array}{c}\text { Ya } \\
\text { n }(\boldsymbol{\%})\end{array}$ & $\begin{array}{l}\text { Tidak } \\
\mathbf{n}(\boldsymbol{\%})\end{array}$ \\
\hline Kenderaan: & & \\
$\quad$ Motosikal & $274(84.3)$ & $51(15.7)$ \\
$\quad$ Kereta & $59(18.2)$ & $266(81.8)$ \\
Pengangkutan awam: & & $161(49.5)$ \\
Bas ekspres & $164(50.5)$ & $284(87.4)$ \\
LRT & $41(12.6)$ & $264(81.2)$ \\
Komuter/kereta api & $61(18.8)$ & $1454.6)$ \\
Teksi & $180(55.4)$ & \\
\hline
\end{tabular}

(iv) Perkhidmatan perubatan

Berdasarkan aspek perkhidmatan perubatan, kerajaaan sedaya upaya menyediakan kemudahan ini sehingga ke kawasan pedalaman. Menyedari kepentingan penjagaan kesihatan, masyarakat orang Asli tidak janggal untuk mendapatkan rawatan perubatan yang disediakan oleh kerajaan. Walaupun hospital dan klinik tidak terdapat di tempat mereka, komuniti orang Asli kini mengambil inisiatif untuk ke bandar bagi mendapatkan rawatan doktor. Usaha kerajaan memberi bantuan hingga ke kawasan pedalaman mendapat reaksi positif komuniti orang Asli apabila penggunaan perkhidmatan perubatan berada pada peratusan yang amat tinggi. Bagi perkhidmatan klinik/hospital kerajaan, jumlah orang Asli yang pernah menggunakan perkhidmatan tersebut adalah 92.6\%, seterusnya adalah perkhidmatan klinik/hospital swasta yang mencatat peratusan penggunaan sebanyak $60.9 \%$, dan klinik gigi mencatat peratusan sebanyak 52.9\% (Jadual 5).

Hal ini membuktikan bahawa komuniti orang Asli telah membudayakan kehidupan yang mementingkan penjagaan kesihatan. Kemasukan elemen perubatan moden telah diterima oleh komuniti orang Asli bagi menyelesaikan masalah berkaitan kesihatan. Pemikiran mereka tidak lagi dicengkam kepercayaan dahulu kala yang mengaitkan setiap jenis penyakit dengat unsur atau pengaruh alam dan hanya boleh diubati oleh pawang atau bomoh (Hassan, 1998). Pemikiran mereka telah berubah dengan menerima bentuk rawatan yang berasaskan sains dan teknologi. Walaupun perkhidmatan klinik dan hospital berada jauh di bandar, masyarakat orang Asli masih sedaya upaya mendapatkan rawatan doktor bagi merawat penyakit yang dihidapi. Justeru itu, hal ini dapat menjelaskan bahawa penggunaan perkhidmatan dari segi perubatan merupakan elemen 
dalam pembangunan yang dimanifestasikan sebagai salah satu petunjuk kepada pembangunan komuniti dalam kalangan masyarakat orang Asli.

Jadual 5. Penggunaan perkhidmatan perubatan

\begin{tabular}{lcc}
\hline \multicolumn{1}{c}{ Perkhidmatan perubatan } & \multicolumn{2}{c}{ Penggunaan } \\
\cline { 2 - 3 } & Ya & Tidak \\
& $\mathbf{n}(\boldsymbol{\%})$ & $24(7.4)$ \\
Klinik/ Hospital Kerajaan & $301(92.6)$ & $127(39.1)$ \\
Klinik/ Hospital Swasta & $198(60.9)$ & $153(7.1)$ \\
Klinik Gigi & $172(2.9)$ & \\
\hline
\end{tabular}

(v) Perkhidmatan simpanan

Perkhidmatan simpanan merupakan perkhidmatan yang penting dalam kemajuan sesebuah negara. Perkhidmatan ini menawarkan kemudahan simpanan wang dan harta berbentuk emas dan barang-barang berharga. Kemudahan ini kebiasaannya terdapat di bandar dan berkembang pesat dengan kewujudan pelbagai jenis bank yang menawarkan perkhidmatan yang sama. Bagi komuniti orang Asli, perkhidmatan seperti ini merupakan salah satu perkhidmatan yang tidak asing bagi mereka. Hasil kajian mendapati, penggunaan khidmat perbankan adalah $49.8 \%$ dari keseluruhan responden (Jadual 6). Keadaaan ini menunjukkan penerimaan masyarakat orang Asli terhadap khidmat simpanan wang dan harta terhadap agen yang selamat dan memberi kelebihan dalam setiap simpanan. Walaupun perkhidmatannya jauh di bandar, keadaan ini tidak menjadi penghalang untuk mereka mendapatkan perkhidmatan tersebut. Inisiatif perkhidmatan perbankan kerajaan seperti khidmat perbankan seperti Bank Simpanan Nasional mendapat reaksi positif komuniti orang Asli. Perubahan mentaliti yang dahulunya mencengkam kehidupan masyarakat orang Asli dengan menyimpan wang di rumah telah berubah ke arah simpanan yang mengikut kemajuan semasa. Hal ini menunjukkan keterbukaan masyarakat orang Asli dalam menerima pembangunan sehingga menjadikan kehidupan mereka lebih berkualiti.

Jadual 6. Penggunaan perkhidmatan simpanan dan pajakan

\begin{tabular}{lcc}
\hline Perkhidmatan & \multicolumn{2}{c}{ Penggunaan } \\
\cline { 2 - 3 } & $\begin{array}{c}\text { Ya } \\
\mathbf{n}(\boldsymbol{\%})\end{array}$ & $\begin{array}{c}\text { Tidak } \\
\mathbf{n}(\boldsymbol{\%})\end{array}$ \\
\hline Simpanan dan pajakan: & $162(49.8)$ & $163(50.2)$ \\
Bank & $34(10.5)$ & $291(89.5)$ \\
Kedai pajak & & \\
\hline
\end{tabular}

\section{Kesimpulan}

Makalah ini memberikan tumpuan kepada penggunaan barangan dan perkhidmatan moden dalam kalangan komuniti orang Asli di daerah Jelebu Negeri Sembilan. Komuniti orang Asli seperti komuniti lain telah terserap ke dalam budaya arus kemodenan masyarakat Malaysia. Secara keseluruhannya, orang Asli semakin terdedah dengan penggunaan arus perdana. Elemen-elemen pembangunan telah mula diterima dan menyelinap masuk dalam kehidupan masyarakat orang Asli. Pembangunan komuniti jelas kelihatan apabila masyarakat orang Asli sudah mula berubah 
nilai dan menerima pemodenan yang disediakan. Oleh itu, penggunaan barangan dan perkhidmatan dalam kalangan masyarakat orang Asli merupakan manifestasi penerimaan pembangunan yang disediakan. Justeru itu, penggunaan barangan dan perkhidmatan merupakan salah satu petunjuk kepada pembangunan komuniti dalam kalangan masyarakat orang Asli.

Namun begitu, terdapat banyak halangan dan cabaran yang terpaksa mereka tempuhi kerana kurangnya pengetahuan yang berkaitan dengan pengurusan kewangan dan pada waktu yang sama menjadi mangsa kepada komuniti peniaga yang cuba mengaut keuntungan daripada kelemahan orang Asli. Mereka menjadi sasaran kepada barangan mewah, namun tidak mampu untuk memilikinya secara tunai sehingga terperangkap dalam jerat hutang. Lantaran itu, adalah menjadi satu keperluan untuk mendedahkan masyarakat yang didakwa sebagai masyarakat terpinggir ini kepada pengetahuan yang berkaitan dengan kepenggunaan. Senario konsumerisme dalam komuniti orang Asli sudah berubah dan stigma yang menyatakan mereka terpinggir daripada arus pemodenan adalah tidak benar. Kesedaran orang Asli terhadap pemodenan sudah cukup menggambarkan bahawa mereka juga inginkan perubahan, namun kedaifan dan kemiskinan sahaja yang menghambat mereka. Seandainya kepompong ini dapat dipecahkan, komuniti orang Asli berupaya membangun seiring dengan masyarakat Malaysia yang lain. Oleh itu, semua pihak perlu berganding bahu dan membuka mata dalam membangunkan komuniti orang Asli dengan penuh rasa tanggungjawab dan bukannya sekadar untuk kepentingan sematamata.

\section{Rujukan}

Babbie, E. (2001). Practice of social research (8th ed.). New York, Wardsworth Publishing Company.

Batterby, S. (2009). New consumer values and changing consumer behavior: How to talk to today's consumer. Retrieved from http://ezinearticles.com.

Blackwell, R.D., Miniard, P.W., \& Engel, J.F. (2006). Consumer behavior (10th ed.). USA, Thomson South-Western.

Creswell, J.R. (2009). Research design: Qualitative, quantitative and mixed methods approaches (3rd ed.). London, SAGE Publication.

Fatan, H.Y. (2008). Pendidikan masyarakat orang Asli. In Ma'rof, R., \& Sarjit, S.G. (Eds.), Orang Asli: Isu, transformasi dan cabaran (pp. 162-177). Serdang, Universiti Putra Malaysia.

Gomes, A.G. (2004). Looking for money: Capitalism and modernity in an orang Asli village. Melbourne, COAC, Kuala Lumpur and Trans Pacific Press.

Gordon, C. (2010). The objects of the whites: Commodities and consumerism among the XikrinKayapó (Mebengokre) of Amazonia. Journal of the Society for the Anthropology of Lowland South America, 8(2), 1-20.

Government of South Australia. (2015). Aboriginal community \& consumer engagement strategy. Retrieved from https://www.sahealth.sa.gov.au

Groves, R.G. (1999). Fourth world consumer culture: Emerging consumer cultures in remote Aboriginal communities of North-Western Australia ( $\mathrm{PhD}$ dissertation). Retrieved from Edith Cowan University, Australia. 
Hanina, H.H., \& Asnarulkhadi, A.S. (2008). Kesihatan dan perubatan masyarakat orang Asli. In Ma'rof, R., \& Sarjit, S.G. (Eds.), Orang Asli: Isu, transformasi dan cabaran (pp. 113-142). Serdang, Universiti Putra Malaysia.

Harmsworth, G.R., \& Awatere, S. (2013). Indigenous Māori knowledge and perspectives of ecosystems In Dymond, J.R. (Ed.), Ecosystem services in New Zealand conditions and trends (pp. 274-286). Lincoln, New Zealand, Manaaki Whenua Press.

Hassan, M.N. (1998). Masyarakat orang Asli dan Akta 134 (Akta Orang Asli): Kaitannya dengan pembangunan. In Hassan, M.N. (Ed.), Warga pribumi menghadapi cabaran pembangunan (pp. 88-120). Bangi, Universiti Kebangsaan Malaysia.

Hassan, M.N. (2000). Pembangunan dan Peminggiran: Kes orang Asli. In Abdul Rahman, E. (Ed.), Negara pemasaran dan pemodenan Malaysia. Bangi, Universiti Kebangsaan Malaysia.

Hassan, M.N. (2018). Budaya keusahawanan orang Asli. In Ma'rof, R., \& Sarjit, S.G. (Eds.), Orang Asli: Isu, transformasi dan cabaran (pp. 54-71). Serdang, Universiti Putra Malaysia.

Hawkins, D.I., Mothersbaugh, D.L., \& Best, R.J. (2007). Consumer behavior: Building marketing strategy (10th ed.). USA, McGraw-Hill.

Horrobin, S. (2006). Immortality, human nature, the value of life and the value of life extension. Bioethics, 20(6), 279-292.

Jabatan Kemajuan Orang Asli. (2011). Pelan strategik Jabatan Kemajuan Orang Asli 20112015. Kuala Lumpur, Department of Orang Asli Development (JAKOA).

Jabatan Kemajuan Orang Asli. (2016). Data maklumat asas orang Asli 2016. Kuala Lumpur, Jabatan Kemajuan Orang Asli Malaysia.

Lee, H.Z., Vivien, W.C.Y., Azima, A.M., Mal, K.S., \& Geraldine, K.L.C. (2018). Perubahan sosioekonomi komuniti orang Asli Jakun akibat Rancangan Penempatan Semula: Satu kajian kes di RPS Runchang, Pahang. Malaysian Journal of Society and Space, 14(4), 127-141.

Liu-Thompkins, Y. (2019). Acculturation and consumer behavior: A theoretical model. Retrieved from https://www.yupingliu.com.

Love, T., Finsterwalder, J., \& Tombs, A. (2018). Māori knowledge and consumer tribes. Mai Journal, 7(1), 44-50.

Ma'rof, R., \& Mohd Taufiq, M. (2008). Orang Asli: Ekonomi pasaran dan konsumerisme. In Ma'rof, R., \& Sarjit, S.G. (Eds.), Orang Asli: Isu, transformasi dan cabaran (pp. 204-221). Serdang, Universiti Putra Malaysia.

Mustaffa, O. (2008). Rancangan Pengumpulan Semula (RPS) masyarakat orang Asli: Pencapaian dan cabaran. In Ma'rof, R., \& Sarjit, S.G. (Eds.), Orang Asli: Isu, transformasi dan cabaran (pp. 178-203). Serdang, Universiti Putra Malaysia.

Ramlee, A. (2001). Peralihan ekonomi masyarakat orang Asli Terengganu: Satu sudut ekonomi persekitaran ( $\mathrm{PhD}$ dissertation). Retrieved from Universiti Sains Malaysia, Pulau Pinang.

Rosnon, M.R. (2010). Penggunaan barangan dan perkhidmatan sebagai petunjuk pembangunan komuniti orang Asli Di daerah Jelebu, Negeri Sembilan (Master dissertation). Retrieved from Universiti Putra Malaysia, Serdang.

Rosnon, M.R. (2014). Challenges on the orang Asli's Rights in mainstream education in Malaysia: An overview. Malaysian Journal on Human Rights, 57-72.

Rosnon, M.R. (2016). Indigenous education policies in Malaysia and Australia: A study of the recognition of indigenous rights and self-determination ( $\mathrm{PhD}$ dissertation). Retrieved from University of South Australia, Adelaide, South Australia. 
Rosnon, M.R., \& Asnarulkhadi, A.S. (2018). Wacana dasar dan pembangunan orang Asli dalam pembangunan kontemporari orang Asli. In Sarjit, S.G., \& Mohd Roslan, R. (Eds.), Pembangunan kontemporari orang Asli (pp. 12-37). Serdang, Universiti Putra Malaysia.

Rosnon, M.R., Sarjit, S.G., \& Ma'rof, R. (2018a). Acculturation of consumerism among the orang Asli community in Mersing, Johor. Jurnal Pengguna Malaysia, 31(Dis 2018), 41-56.

Rosnon, M.R., Sarjit, S.G., \& Ma'rof, R. (2018b). Konsumerisme orang Asli. In Sarjit, S.G., \& Mohd Roslan, R. (Eds.), Pembangunan kontemporari orang Asli (pp. 148-168). Serdang, Universiti Putra Malaysia.

Sarjit, S.G., Rosnon, M.R., \& Ma'rof, R. (2010). Acculturation of consumerism among the orang Asli community in Jelebu, Negeri Sembilan. Petanika Journal Social Sciences and Humanities, 18(2), 321-331.

Seow, T.W., \& Mohd Nur Syufaat, J. (2018). Pembangunan sosioekonomi orang Asli. In Sarjit, S.G., \& Mohd Roslan, R. (Eds.), Pembangunan kontemporari orang Asli (pp. 101-117). Serdang, Universiti Putra Malaysia.

Silberg, D.M. (2001). Doing dissertations in politics a student guide. London, Routledge.

Wong, E. (2016). Comparative analysis of consumer behavior: Effects of cultural differences between Western and Eastern countries on visual perception and memory (Master dissertation). Retrieved from Ca' Foscari University of Venice. 